\title{
A class of degenerate elliptic equations with nonlinear boundary conditions - WITHDRAWAL
}

Zhuoran Du, Yanqin Fang, and Changfeng Gui

Published by the Canadian Mathematical Society, June 27, 2016

An article by Du, Fang, and Gui [1] was officially withdrawn on February 14, 2017 (after online publication), by request of the authors, due to an error in a proof. The article will not appear in a future print publication of the Canadian Mathematical Bulletin, and the original article has been marked accordingly to reflect the withdrawal.

\section{Reference}

[1] Z. Du, Y. Fang, and C. Gui, A class of degenerate elliptic equations with nonlinear boundary conditions. Canad. Math. Bull. https://doi.org/10.4153/CJM-2016-017-x.

Published online on Cambridge Core A pril 12, 2019. 